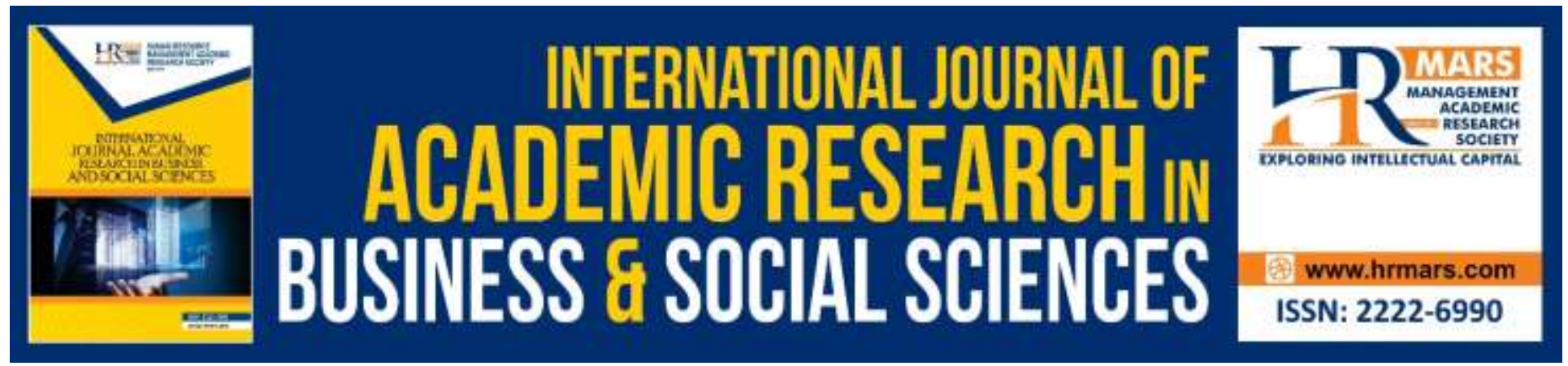

\title{
Women in Sport Leadership Positions in Malaysia: Issues and Challenges
}

Mirian P. Aman, Suharyanti Hanapi, Aminuddin Yusof, Abu Bakar Razali, \& Roxana Dev Omar Dev

To Link this Article: http://dx.doi.org/10.6007/IJARBSS/v9-i11/6715

DOI: 10.6007/IJARBSS/v9-i11/6715

Received: 04 October 2019, Revised: 23 October 2019, Accepted: 14 November 2019

Published Online: 22 November 2019

In-Text Citation: (Aman et al, 2019)

To Cite this Article: Aman, M. P., Hanapi, S., Yusof, A., Razali, A. B. \& Dev, R. D. O. (2019). Women in Sport Leadership Positions in Malaysia: Issues and Challenges. International Journal of Academic Research in Business and Social Sciences, 9(11), 1506-1519.

Copyright: (c) 2019 The Author(s)

Published by Human Resource Management Academic Research Society (www.hrmars.com)

This article is published under the Creative Commons Attribution (CC BY 4.0) license. Anyone may reproduce, distribute, translate and create derivative works of this article (for both commercial and non-commercial purposes), subject to full attribution to the original publication and authors. The full terms of this license may be seen at: $\underline{\text { http://creativecommons.org/licences/by/4.0/legalcode }}$

Vol. 9, No. 11, 2019, Pg. 1506 - 1519

Full Terms \& Conditions of access and use can be found at http://hrmars.com/index.php/pages/detail/publication-ethics 


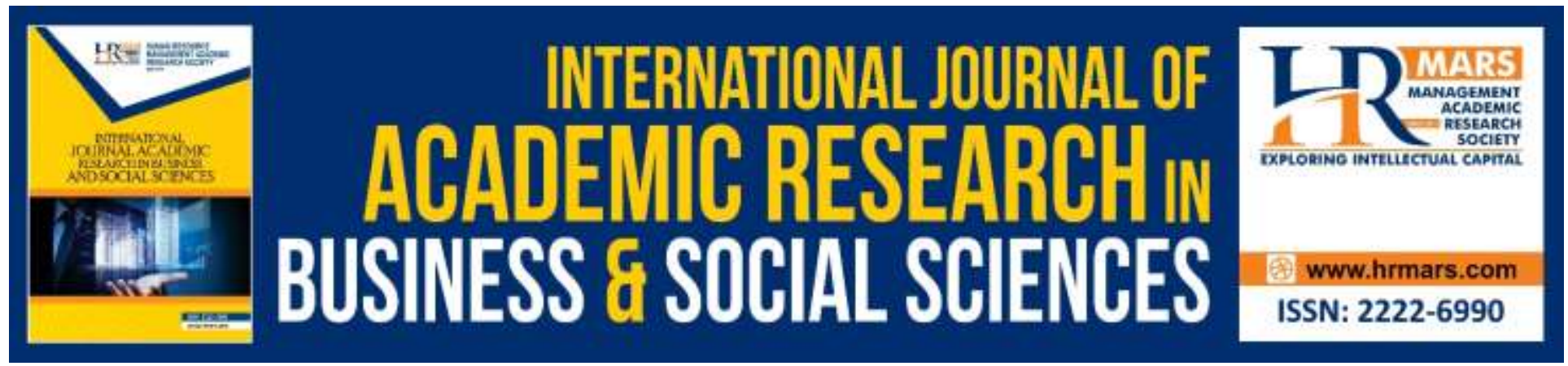

\title{
Women in Sport Leadership Positions in Malaysia: Issues and Challenges
}

\author{
Mirian P. Aman ${ }^{1}$, Suharyanti Hanapi², Aminuddin Yusof ${ }^{2}$, Abu \\ Bakar Razali², \& Roxana Dev Omar Dev² \\ ${ }^{1}$ College of Sports, Physical Education and Recreation, Mindanao State University, Marawi, \\ ${ }^{2}$ Philippines, Faculty of Educational Studies, Universiti Putra Malaysia (UPM), MALAYSIA
}

\begin{abstract}
Leadership is the process of influencing an organized group toward accomplishing common set goals, and it can also be defined as the ability of an individual to establish direction for a working group of individuals who gain commitment from this group of members to this direction and who then motivate these members to achieve the direction's outcomes. Leadership, however, requires neither gender qualifications nor someone with communal or agentic characteristics but one with instinct potential to fulfil responsibilities. The purpose of the current study was to investigate how women leaders perceive the underrepresentation of women in top sport leadership positions in Malaysia. Guided by an interpretative phenomenological analysis approach, data were collected through in-depth, face to face semi structured interviews, observations and document analysis involving seven women leaders in national sport organizations. The findings showed that women were underrepresented in top leadership positions and the subjects revealed perceived barriers which they believe impede women's ascend in top leadership positions. These barriers include personal limitations which include self-limiting behaviors and work-life conflict among women; sociocultural factors consisting of traditional practices and society's perceptions; and organizational factors consisting of all-men's network, gender discrimination and conflict among women. It was concluded that the underrepresentation of women sport leaders is a vicious cycle where there is a chain of events in which the response to one difficulty creates a new problem that intensify and aggravate the original situation.
\end{abstract}

Keywords: Gender, Leadership, Sports, Malaysia

\section{Introduction}

Leadership is the process of influencing an organized group toward accomplishing common set goals (Aristotelis, Kaloyan, \& Evangelos, 2013; Roach \& Behling, 1984; Saybani,Yusof, 
Soon, Hassan, \& Zardoshtian, 2015; Silva, 2016). It is also defined as the ability of an individual to establish direction for a working group of individuals who gain commitment from this group of members to this direction and who then motivate these members to achieve the direction's outcomes (Conger, 1992). Leadership, however, requires neither gender qualifications nor someone with communal or agentic characteristics but one with instinct potential to fulfil responsibilities (Saybani, Yusof, Soon, \& Hassan, 2015). However, the literature suggests leadership has been predominantly a male prerogative, such as, in the corporate, political, military, and other sectors of society (Eagly \& Karau, 2002), and this does not exclude the realm of sport. Women are less likely than men to be associated with leadership (Latu, Mast, Lammers, \& Bombari, 2013), and women face a disproportionate number of life challenges that reduces their ability to achieve their full potential. Although women have gained increased access to supervisory and middle management positions, they remain quite rare as elite leaders and top executives (Eagly \& Karau, 2002).

Although there is an increased opportunities for girls and women to participate in sport, they remain underrepresented within all areas of leadership at all levels of sport (Burton, 2015; M'mbaha \& Chepyator-Thomson, 2018). In many studies (see Lovett \& Lowry, 1994; Sagas, Cunningham \& Teed, 2006, etc.), despite formal guarantees of equality, the overall rate of progress for women particularly those from the poorest and marginalized regions of the world have been slow. Many barriers and challenges to equitable employment opportunities remain, including stereotypical attitudes towards women and sport. The study of Sartore and Cunningham (2007) proposes that gender-role meanings and stereotypes associated with social and sport ideology may limit the capacity of women within the sport context. In addition, given sport as traditionally a male domain, the involvement of women in sport challenges a multitude of gender stereotypes. Specifically, the globalization of women's movement of equity which started in developed and western countries have reached many parts of the world, including the South East Asia of which Malaysia is no exception. Megat Daud, Radzi, Abdullah, and Johari (2013) exemplified that women in top-level positions in sport is still lacking in numbers in contrast to the population and lower than their male counterparts.

Previous research mostly focused only to identify the barriers and challenges of women in sport leadership, rather than investigating the impact of those barriers to the underrepresentation of women. Meanwhile others evaluate the effectiveness of leadership roles when it is enacted by different gender. The descriptive and quantitative nature of the previous studies help the current study, but somehow, failed to uncover some issue in-depth, thus fall short to provide deeper explanation on how the issue of underrepresentation of women in leadership positions in sport organizations affected the group under study. To this extent, the current study attempted to further the extant literature. By employing qualitative research methods that investigated the phenomenon in-depth, the current study goes beyond statistics and demographic description, rather focused more in providing rich descriptions and analyses of this phenomenon. Applying three related theoretical perspectives of role congruity, homologous reproduction and pipeline problem in a less sited research setting in the context of women in sport leadership, this qualitative study attempted to uncover the social, personal, and 
organizational processes involved that impacted the underrepresentation of women in leadership positions of sport organizations.

Research on sport leadership experiences of Malaysian women in sport organizations receives very little attention among sport management researchers. In the Malaysian context of sport, women in leadership position continue to juggle their personality and manage many things in order to be relevant and carry out a great effort not to be discriminated. Although, Malaysian women have enjoyed opportunities to participate in the workforce in the country relatively increasing from $43.05 \%$ in 2008 to $50.79 \%$ in 2017 and there have been women's policy that emphasized on women's equity of $30 \%$ in managerial and leadership position in public sector yet, women's representation in sport associations are still low than their male counterparts (Megat Daud, Radzi, Abdullah, \& Johari, 2013). Given the dearth of research of women in sport leadership in Malaysia this study explored the lived experiences of women leaders who have striven the top leadership positions in national sport organizations. By giving voices to women top leaders with their experiences of the phenomenon provided in-depth understanding, helped explain and define the underrepresentation of women in sport leadership in sport organizations.

There have been theories that explained the underrepresentation of women in leadership. The role congruity theory initiated by Eagly and Diekman (2005) which hypothesized that women's underrepresentation in leadership is due to the incongruence of gender and leadership roles that contributed to prejudices towards women's aspiration for leadership positions. Moreover, homologous reproduction (Lovett \& Lowry, 1994; Sagas, Cunningham \& Teed, 2006), is an organizational barrier believed that dominant group (i.e., men in the study of Kanter, 1977) are likely to hire subordinates of the same gender. Pipeline problem (Massengale, 2009; Monroe \& Chiu, 2010) are social and personal limitations which are believed to impede women's representation in leadership. Pipeline problem is a notion that due to the sparse representation of women in the lower level of administrative roles (Turkel, 2004), thus for a career move into administration and hiring of women in top leadership is even more difficult.

\section{Methods}

This study employed a qualitative phenomenological research design. The data collection was carried out using face-to-face semi-structured interviews, observations and document analysis. Seven participants who are women top leaders, were chosen based on the criterion of being a member of the Executive Board, General Secretary, Head of the Department, President, Deputy President, and Vice President of sport organizations in Malaysia, with at least two years' experience in that position.

A total of 21 face-to-face interviews were conducted, that is, three interviews for each participant which lasted an average of 41 minutes each participant. Alongside interviews, observations were conducted twice each participant on meetings and events where they are involved where field notes were done. Field notes were also done during interviews that served the researchers personal observation on the things the digital recorder could not see, like the emphases placed by the participants on certain issues and words, their facial expressions and the emotion they displayed. 
The current study employed constant comparative analysis in order to have a close connection and better grasp with the data. It is a data-analytic process whereby each interpretation and findings is compared with the existing findings as it emerges from the data analysis and it is carried out throughout the analysis until properties of all categories and its relationship between other categories are clear (Parry, 2011). Analysis began by organizing data from documents, observations field notes and interview transcripts. Constant revisiting on the field notes and transcripts allowed the researcher to immerse herself in the data and obtain the sense of it. Analysis continued through initial coding process (Charmaz's, 2006). Developing themes to the data was the next step; codes identified are then group together to form broader and overarching themes. It is important to note that all the participants in the study consented verbally and in writing of their participation in the study. It is also important to note that because they hold important positions in their respective institutions, and due to some sensitive issues with the nature and direction of the study, the utmost care was attended to make sure that the confidentiality of the study is ensured. All the participants' names and their respective institutions were given pesudonyms, and also the data sets were kept at a safe place at the researchers' institution, to which the access to these data sets are only accessible to the researchers.

\section{Results}

The main theme that emerged from the data was perceived barriers, which was further coded to three sub-themes: (1) personal limitations, (2) sociocultural factors, and (3) organizational factors. The first sub-theme was the barrier pertaining to "personal limitations" whereby these limitations specifically described self-limiting behaviors and work-life conflict as barriers. The second sub-theme was "sociocultural factors" consisting of traditional and cultural practices, and society's perception. Traditional and cultural practices were also found to influence women leaders' underrepresentation which is evident for a country (like Malaysia) characterized by a collectivist society (Hofstede \& Hofstede, 2005). Society's perception is another contributing factor to the issue whereby even in a contemporary society like Malaysia is still not accepting women when leadership is concern. The third sub-theme, "organizational factors" is largely talked among the participants. These factors in the organization include allmen's network, gender discrimination and conflict among women.

The word barrier is generally defined as that which prevents or controls advancement, access or progress (Oxford Dictionary, 2000). It is an events or conditions either within the person or in his or her environment that make career progression difficult (Swanson \& Woitke, 1997). Sport organizations an area with diverse ideologies and sociocultural attributes, certain barriers were evident which consequently affect women's leadership advancement. The participants in this study emphasized barriers not only from the environment where women tried to get access, rather also pointed barriers pertaining to personal matters. The participants in this study refer to women in general rather than the barriers they dealt with as individual. Nevertheless, there were barriers women need to address in order to navigate in the situation which they perceived as 
contributing factors to the persistent low representation of women in top leadership positions of sport organizations.

The participants in this study identified three barriers they perceived to limit women leaders' upward mobility in top leadership positions, namely: 1) personal limitations, 2) sociocultural factors, and, 3) organizational factors. The first barrier the participants mostly talked about is "personal limitations" where they identified self-limiting behavior and work-life conflict inhibited women to deliver their full potentials. The second barrier the participants perceived was related to sociocultural factors such that "traditional and cultural practices" of the country afforded power and status to men in the society; and "society's perception" whereby the society perceived particular roles for particular gender, and women being the recipient of communal characteristics, thus perceived incapable of handling agentic characteristics attributed to a leader. The third barrier the participants pointed out was the "organizational factors" which consists of situations or condition in the organizations such as all-men's network, gender discrimination, and conflict among women.

\section{Personal Limitations Factors}

The participants cited self-limiting behavior of women was one of the reasons why they are less likely seen and hardly ascending in the leadership pipeline. The participants perceived women fail to offer themselves in the position and not bold enough to promote themselves even if they are qualified. According to Interviewee 1 "it's not just few women being selected but few women offer themselves for selection...like I said a lot of women don't step up and take up the challenge" and "women themselves are afraid to come out, they don't want to be in front", Interviewee 2 added. Interviewee 3 considered self-limiting behavior as major barrier why women are still few in the top leadership positions: "I think it's a major barrier because they [women] wouldn't say... I offer myself to be a leader. They [women] would think twice or three times before actually accepting or going for the role...so, I think it takes time because a lot of women don't see themselves as a leader and women don't see themselves as being able to make decision or being able to have a voice within an organization."

Lack of self-confidence is another limiting behavior the participants perceived that hinder women in the top leadership position. Interviewee 4 believed that there are many women who can be top leaders but are less confident to come-out and not willing to take risk: "There are many women can be inspired to be top leaders. But again it is a quality and a lot is up to the person herself whether she wanted to come out or not...and some people [women] are just too shy to speak up, less self-esteem. They are not brave enough to conquer this wall. The wall is too huge, too big for them to conquer."

The participants referred difficulties concerning work-life among women as reason for not achieving top leadership positions. Women's perceived gender roles as mother, wife and homemaker are life demanding and work conflicting roles, thus, is one of the reasons why few women ascend to top leadership positions of sport organizations. The participants believed that because of family responsibilities women declined to hold position especially if she is married and has children. Interviewee 5 recalled one specific situation: "Why lack of women in sport 
organization is example, last time when we call them for meeting 3pm, they don't come...hey...It's so difficult, I have to take care of my daughter. So, all the guys cannot wait for them. So, that's how it started. The commitment from the women itself is not there, compared to men. Because naturally in life, men are like that, they are free; we [women] have to take care of the house, of the children. So, when we call them, every time, "I'm so busy", "I have to fetch my daughter from school" they don't put the focus on that."

\section{Sociocultural Factors}

Society, culture and tradition played a significant impression as to how women should behave in the community. As the societies preconceive notion of women being the weaker sex (Couturier \& Chepko, 2001), their social gender role were also perceived as not aligned to any sport pursuit, particularly at the management level because sport is historically noted as men's world. Additionally, in most culture and as tradition, women's gender role is expected to be opposite from men. Thereby, women are expected to perform communal tasks such as homemakers, they are expected to be nurturing and compassionate, whereas, men lead the family, independent, aggressive and competent. The social roles perceived for women were more attuned for subordinating roles. While men's perceived roles were likely accustomed to lead and dominate. Such perception for two different gender roles segregated men and women to perform different social roles which inhibit women to seek for positions traditionally occupied by men. While men were traditionally seen as the leader and sport is historically noted as a men's world, thus women's characteristics do not qualify in such domain.

In Malaysia's traditional social arrangement, the position of power and authority has inherently placed males as the heads or leaders (Saadin, Ramli, Johari, \& Harin 2016). The participants of this study perceived that one of the reasons why women are less represented in top leadership positions were because of such practices where women find it difficult to change. According to Interviewee 2 "...it's the culture that is difficult to change. To build that relationship with that culture you have to have a man with a man because the way the culture is that the man will not see a woman as a leader ever." Additionally, she further pointed out that it is not a custom for women to be leaders because culture assigned them as secondary to men: "I think it's Malaysia itself. Because I would say in our culture and in our environment at the moment it's still not acceptable for a woman to be a leader. The tradition still stands. It is still not considered a norm for a woman to be a leader...if you are brought up to consider women as a secondary role and men has been taught since young that men are leaders and leader of the family, thus therefore leader of everything else and women are supporting, is a supporting role to that leader, to the leadership role of a father, or a brother of the household. Thus, I would say that it happens a lot in Malaysia because that is how the education and the way they have been brought up and it's the culture."

Another emerging perceived barrier from the data was society's (negative) perceptions towards women leaders. The participants believed that because of the society's preconceived negative views towards women as being unfit for leadership position, women were then restrained to pursue top leadership positions. The consequence of society's perception placed 
women marginalized in the organization. Interviewee 6 cited the example that time when she was considered for a position where society doubted a woman for the job: "Sometimes people have this perception, I myself had this...it's like, when I first offered a position, I didn't think they were serious, because before me they had five men, I was number six, the first woman...but it's just people's perception... will the lady take the job? They have this self-doubt, they say that can we do it that we are women."

\section{Organizational Factors}

Sport as an organization is a complicated institution. Not only because it is predominantly dominated by men, but it is also an avenue where diverse perspectives, interests, and individual characteristics played together. The participants in the study perceived that as women navigated to advance leadership path there are several organizational factors women perceived as barriers. The participants believed that the dominance of men in the organization is an obvious manifestation that hinders women's access because men have been creating a network and positively promoting each other. The participants believed that men were already in the organization since then and they have established network among themselves. This network allowed men to facilitate easy access within organization, accessing more opportunities and privileges, and more promotion for men's favor. Thus, the consequence of all men's network made it harder for women to penetrate access and establish connection within the system.

Interviewee 5 considered men's network a barrier difficult to fight against in the organization and considered sport as a men's world: “...because women seem to be in difficult [situation] to fight against all the men, it's totally men's world. There is always a feeling to protect. There is always a feeling of we are the weak ones, we should not be doing that, culturally, even religiously. Because people do not think sports as a general thing, when they see sports, they see gender, when they see sport, they see a different way of moving things...It's a men's world. The men will carry all the men only but never will bring out the women."

In sport and leadership, gender discrimination seems to be always an issue. Literatures may have told us that sport and leadership are favorably seen when it is acted by men, while women having communal characteristics were not positively favored for such endeavor. This perspective brought unfair and bias treatment among women being the recipient of the "weaker sex" notion. Because of such prejudice women were discriminated in terms of opportunities, access, privileges and support. Interviewee 7 shared her story how she was treated unfairly in the organization where she is serving with: "At my experience with the current organization, I have some problem earlier. I was also one of the leaders in the women and sports in the $X$ Federation where the guys don't allow, they don't like people like us who are very firm, who know about sports, who can handle situation, who can deliver. There are some guys [who are] a bit of kind of unsure [of themselves], so they have to talk about us to their counterparts negatively, because they have got groups basically."

With organizational groupings it created sport politics influencing individual to monopolize the system. Interviewee 5 hesitated to stand for election for her sport organization because of such practices and the belief that men are not still accepting women as far as 
leadership is concerned: "But sometimes, the politics are involved. And I think to myself, is it worthwhile getting involved in those kinds of politics? You know, I mean I'm at this age where I want to have stress-free life. Looking at the situation, I'm being selfish but I just don't want to be embroiled. It's like, the X Council now they ask me for help in the education committee, I said, "Okay fine, I'Il help you." Women's committee if they want my help, "Fine I'll help you." But you know, to go and stand for election and sit in the board meeting and then...in certain ways, yes, I mean some of the men are still not very accepting women - leaders are concern."

Surprising it may seem but among the barriers the participants perceived that inhibit women's access in the organization is women themselves. The participants acknowledged that it was also a barrier when women have conflict with other women in the organization. The conflict which the participants referred to do not only consists of organizational conflict but in some cases it became personal. The participants considered that there is also politics among women in the organization. Interviewee 7 affirmed to what she learned from another sport leader who said "woman will kill other woman." She cited an example of how she has been doubted for playing politics: "I've got this experience you have to put this. I'm in-charge of woman and sport; I have to develop a lot of women. Basically, I have to help also the ex-athletes who are keen but they cannot come into the room. How I'm gonna pull them into the room, when you [other woman] don't like them? You're [other woman] pushing them out. When I bring them in, then you say I'm playing politics, you see? This perception of woman sometimes also we have to consider. I agree with one of the sport leader was telling me "woman will kill the other woman." And this is going on in our country." Interviewee 7 also believed that women themselves are their own obstacles and when there are more women in the organization, there were also more gossiping.

\section{Discussion}

All of the seven women top leaders interviewed perceived several barriers impeding women's representation in the sport organizations of Malaysia. One of which was barrier pertaining to personal limitations, such as those impediments attributed to women's shortcomings. Self-limiting behaviors of women was one of the barriers identified by the participants to cause low representation of women in the higher positions. Wherein, women do not offer themselves for positions despite of their qualifications and they fail to promote themselves for fear of failure and rejection. These findings support the work of Coleman (2001) which revealed that women would only seek for positions upon confirming that they had all the required qualifications, unlike men who would confidently seek for positions even if they were less qualified. As what one of the interviewee emphasized that even if women were already performing the leaders' roles they still remain uncertain of their capabilities. Consistent to the work of Hancock and Hums (2016), self-limiting behaviors of women include perceiving themselves as not professionally qualified for high level management which keep them self believe as incompetent. Hancock and Hums (2016) in their work also found out that women do not seek for Athletic Director (AD) positions and only accustomed to work "behind the scene" or as the "number two." 
These researchers concluded that women's choice to seek positions other than those at the executive level continue the notion that women are not "ready" to be an AD even if they possess viable skill set of a leader. With the rarity of women's self-promotion behaviors, men use these self-promoting behaviors to access leadership positions (Sperandio \& Kagoda, 2010). With these characteristics of women, they remain under achievers in leadership positions. Unlike men, who were found in the study of Sperandio and Kagoda (2010) on one hand to have a well-planned career that target leadership positions, women on the other hand lacked career plan and had no intentions or confidence to seek for leadership positions. These behaviors among women enhance social perception that women are incapable of holding leadership positions because they do not possess perceived leadership qualities as typically seen among men. It also strengthens the belief within sport society that women are more suiting for communal obligations rather than in a pressing condition and high stakes environment, such as in sport management.

The findings of the study also added to the literature on women leaders seeking for higher leadership positions perpetuating the notion of traditional gender roles where child-rearing and other domestic responsibilities are considered to belong to women. Such perception has negative implications on the progress of women into leadership, and resulted in a low representation of women in leadership positions. It is apparent that amidst the changing trends of increased entry of women into formal employment, the traditional gender roles are still upheld. Branson (2007) pointed out, "one thing has stayed the same: it is still women who adjust their lives to accommodate the needs of children, who do what is necessary to make a home, who forego status, income, advancement and independence." Additionally, the finding of the study is consistent to the study conducted by Ismail and Ibrahim (2008) among executive-rank Malaysian women outside sport field. The researchers found out that women's involvement in the family reduces their career commitment with majority of the women respondents agreed that they had less time for career progression due to their family duties. Similar finding was also found in the study of Subramaniam and Arumugam (2013) among Malaysian women managers which suggest that women managers lose out their careers because they prioritize to accommodate their family responsibilities. Additionally, the findings of this study also supports the more recent study conducted by Saadin, et al. (2016) among state secretariats in Perak, Malaysia which also found that work-life responsibilities affect career advancement of female workers in public sector.

Aside from personal limitations and sociocultural perceived barriers women are facing in seeking for top leadership positions of sport organizations, the participants also perceived organizational factors as other impediments women are facing. Organizational-related perceived barriers found in this study include all-men's network, gender discrimination and conflict among women. Leadership can be empowering, enabling, and influence policies and decision making process. However, for women leaders, the male-dominated political environments under which they operate denied them a chance to effectively participate in governance. Some of the struggles that women deal with are deeply embedded in the organizational structures, positions of leadership, and in policies that are hard to change (Hargreaves, 2007). 
The established fraternity known as all-men's network in the sport organizations is also perceived to be a barrier for women seeking top leadership position in sport organizations. In addition to the previous research of Whisenant et al. (2002) and Pedersen and Whisenant (2005), suggesting that sport leadership remains a male domain and hegemonic in nature, the participants interviewed in this study also expressed the perception that sport organizations in Malaysia is predominantly led by men, consequently creating an all-men's network. The consequence of all-men's network leads to the high possibility for men leaders who are in top positions to promote or favor other men in the selection process. With the paucity of women in the top position and the weakness of "all-women's network" counterpart is evident that women seeking for higher leadership position do not get favored or less likely selected in the selection process. According to Whisenant et al. (2002) men already controlled the world of sport since the history including leadership, and they have to keep hold of it and do not have intention to change that situation. One manifestation of all-men's network in Malaysia's sport organization is the emphasis voiced out by the subjects in this study that despite women top leaders' desire to select other women in the top position, but because majority of the voting pool were men - that defeated the purpose and most of the time men leave the voting portion for female empty. Allmen's network is an evident of homologous reproduction (Kanter, 1977) where men systematically guard their power in order to continually gain opportunity and reproduce in number even more. The findings of this study supported to this belief with the existence of allmen's network in the organization. Consequential to this, women were restrained to seek for higher position with the conviction that they would not get the support from men and eventually become complaisant of the organizational norm.

\section{Conclusion}

The underrepresentation of women sport leaders is a vicious cycle where there is a chain of events in which the response to one difficulty creates a new problem that intensify and aggravate the original situation. Specifically, the difficulty of women's representation in sport arena emanate from one issue that leads to another more serious issues. For example, the sociocultural perceptions of the incongruity of gender and leadership roles granted the opportunity for the dominant group to possess power in the position which enable them to have the capacity to take control all opportunities and privileges inaccessible for the minority group (i.e. women), thus inhibit the latter and convince them to start behaving in ways that results in them not being selected for those roles, self-believing that they do not have the capacity to hold leadership roles, and so on.

The biggest challenge for sport organizations in Malaysia is to bring diversity in every area of the organization. Wherein, women, like men, will have the same voice as part of the sport society. It is not only because women need equity for this aspect, but because they are part of the human capital that help contribute in making the sport society and sport organization more effective and meaningful. On the other hand, the challenge for women in sport leadership is to empower every woman where they do not only increase in representation but in letting their voices heard with credibility and integrity. 
INTERNATIONAL JOURNAL OF ACADEMIC RESEARCH IN BUSINESS AND SOCIAL SCIENCES

Vol. 9, No. 11, November, 2019, E-ISSN: 2222-6990 @ 2019 HRMARS

\section{Corresponding Author}

Aminuddin Yusof (PhD), Department of Sports Studies, Faculty of Educational Studies, University Putra Malaysia, 43400 UPM Serdang, Selangor Darul Ehsan, Malaysia.

Email: amin@upm.edu.my

\section{References}

Aristotelis, G., Kaloyan, K., \& Evangelos, B. (2013). Leadership style of Greek soccer coaches. Journal of Physical Education and Sport, 13(3), 348-353.

Branson, D. M. (2007). No Seat at the Table: How Corporate Governance and Law Keep Women out of the Board Room. New York: New York University Press.

Burton, L. J. (2015). Underrepresentation of women in sport leadership: A review of research. Sport Management Review, 18(2), 155-165.

Charmaz, K. (2006). Constructing grounded theory: A practical guide through qualitative analysis. Thousand Oaks, CA: Sage.

Coleman, M. (2001). Achievement against the odds: The female secondary head teachers in England and Wales. School Leadership \& Management, 21(1), 75-100.

Conger, J. A. (1992). Learning to lead. San Francisco: Jossey-Bass.

Couturier, L., \& Chepko, S. (2001). Separate world, separate lives, separate sporting models. In G. L. Cohen (Ed.), Women in Sport: Issues and Controversies (2nd ed., pp. 57-78). Exonhill, MD.: AAHPERD publications.

Eagly, A. H., \& Dickman, A. B. (2005). What is the problem? Prejudice as an attitude-in context. In J. F. Dovidio, P. Glick, \& L. A. Rudman (Eds.), On the nature of prejudice: Fifty years after Allport, 19-35. Maiden, MA: Blackwell

Eagly, A. C., \& Karau, S. . (2002). Role congruity theory of prejudice toward female leaders. Psychological Review, 3, 573-598.

Hancock, M. G., \& Hums, M. A. (2015). A "leaky pipeline"? Factors affecting the career development of senior-level female administrators in NCAA Division I athletic departments. Sport Management Review, 19, 198-210.

Hargreaves, J. (2007). Olympic women: A struggle for recognition. In J. O’Reilley, \& S. K. Cahn (Eds.), Women and Sports in United States: A Documentary Reader. (pp. 209-234). Boston: Northeastern University Press.

Hofstede, G., \& Hofstede, G. J. (2005). Cultures and organizations: Software of the mind (2 ${ }^{\text {nd }}$ ed.) New York: McGraw-Hill.

Ismail, M., \& Ibrahim, M. (2008). Barriers to career progression faced by women. Gender in Management: An International Journal, 23(1), 51-66.

Kanter, R. M. (1977). Men and women of the corporation. New York: Basic Books.

Latu, I. M., Mast, M. S., Lammers, J., \& Bombari, D. (2013). Successful female leaders empower women's behavior in leadership tasks. Journal of Experimental Social Psychology, 49, 444448.

Lovett, D. J., \& Lowry, C. D. (1994). "Good old boys" and "good old girls" clubs: Myth or reality? Journal of Sport Management, 8, 27-35. 
INTERNATIONAL JOURNAL OF ACADEMIC RESEARCH IN BUSINESS AND SOCIAL SCIENCES

Vol. 9, No. 11, November, 2019, E-ISSN: 2222-6990 @ 2019 HRMARS

M'mbaha, J. M., \& Chepyator-Thomson, J. R. (2018). Factors influencing career paths and progress of Kenyan women in sport leadership. Qualitative Research in Sport, Exercise and Health, 1-18.

Massengale, D. (2009). The Underrepresentation of women in interscholastic sport leadership: A qualitative study on the effects of role incongruity (Doctoral Dissertation). UNLV theses/Dissertations/Professional Papers/Capstones. Paper 64.

Daud, M. A. K., Radzi, W., Abdullah, R., \& Johari, F. (2013). The participation of women managers in managing sport: challenges and reality. Life Science, 10(3), 870-878.

Monroe, K. R., \& Chiu, W. F. (2010). Gender equality in the academy: The pipeline problem. PS: Political Science \& Politics, 43(02), 303-308.

Oxford Dictionary. (2000). Oxford University Press: New York

Parry, K. W. (2011). Constant Comparison. The SAGE Encyclopaedia of Social Science Research Methods. Thousand Oaks, CA: Sage

Pedersen, P. M., \& Whisenant, W. A. (2005). Successful when given the opportunity: Investigating gender representation and success rates of interscholastic Athletic Directors. Physical Educator, 62(4), 1-9

Roach, C. F., \& Behling, O. (1984). Functionalism: Basis for an alternate approach to the study of leadership. In J. G. Hunt, D. M. Hosking, C. A. Schriesheim, and R. Stewart (Eds.), Leaders and managers: International perspectives on managerial behavior and leadership. New York: Pergamon Press, pp. 45-62.

Saadin, I., Ramli, K., Johari, H., \& Harin, N. A. (2016). Women and barriers for upward career advancement: A survey at the Perak state secretariat, Ipoh, Perak. Procedia Economics and Finance, 35, 574-581.

Sagas, M., Cunningham, G. B., \& Teed, K. (2006). Examining homologous reproduction in the representation of assistant coaches of women's teams. Sex Roles, 55, 503-510.

Sartore, M. L., \& Cunningham, G. B. (2007). Explaining the under-representation of women in leadership positions of sports organizations: A symbolic interactionist perspective. Quest, 59(2), 244-265.

Saybani, H., Yusof, A., Soon, C. C., Hassan, A., \& Zardoshtian, S. (2015). Athletes' satisfaction as mediator of transformational leadership behaviors of coaches and football players' sport commitment relationship. World Applied Sciences Journal, 21 (10), 1475-1483

Saybani, H., Yusof, A., Soon, C. C., \& Hassan, A. (2015). Transformational leadership and sport commitment: A study of Iranian high schools' football teams. Pertanika Journal of Social Sciences and Humanities, 23(4), 781-792.

Sperandio, J., \& Kagoda, A. M. (2010). Women teachers' aspirations to school leadership in Uganda. International Journal of Educational Management, 24(1), 22-33.

Subramaniam, I. D., \& Arumugam, T. (2013). Barriers to women managers' career progressions in Malaysia government link companies. Australian Journal of Basic Applied Sciences, 7(22), 248-256 
Swanson, J. L., \& Woitke, M. B. (1997). Theory into practice in career assessment for women: Assessment and interventions regarding perceived barriers. Journal of Career Assessment, 5, 443-462.

Turkel, A. R. (2004). The hand that rocks the cradle rocks the boat: The empowerment of women. Journal of the American Academy of Psychoanalysis, 32(1), 41-54.

Whisenant, W. A., Pedersen, P. M., \& Obenour, B. L. (2002). Success and gender: Determining the rate of advancement for intercollegiate athletic directors-Brief report. Sex Roles: A Journal of Research, 5.

Tepus, A. M. (2018). The Relationship between the Capital Market and the Real Economy. The Case of the European Union, International Journal of Academic Research in Accounting, Finance and Management Sciences 8 (2): 164-169.

Franklin, U. E., \& Nahari, A. A. (2018). The Impact of E-Learning on Academic Performance: Preliminary Examination of King Khalid University. International Journal of Academic Research in Progressive Education and Development, 7(1), 83-96. 